\title{
Portuguarañol: língua de conhecimento e tradução da fronteira, em Xirú de Damián Cabrera ${ }^{1}$
}

\author{
Portuguarañol: lengua de conocimiento y traducción de la frontera, en \\ Xirú de Damián Cabrera
}
Portuguarañol: language of knowledge and translation of the border in Damián Cabrera's Xirú

\author{
Dra. Damaris Pereira Santana Lima ${ }^{2}$
}

\begin{abstract}
Resumo
Este trabalho é o resultado de leitura e análise da obra do escritor paraguaio Damián Cabrera. A narrativa do referido autor, apresentada neste texto, é o romance Xirú. Nessa obra, Cabrera apresenta um mundo fronteiriço como protagonista do romance. A narrativa de Cabrera aborda o cenário fronteiriço do Alto Paraná, onde as culturas se misturam, pois, dentre muitas das peculiaridades, as pessoas que povoam esse espaço são denominadas "brasiguayos" (brasileiros/paraguaios), que falam uma língua denominada "portuguarañol" (português/ guarani/ espanhol). Além de apresentar mais esta obra da literatura hispano-americana, este trabalho tem o objetivo de lançar luz sobre diversos conceitos como: crítica biográfica fronteiriça, literaturas de fronteira, estéticas periféricas e especialmente sobre o "plurilinguajeo" que ocorre neste lócus. Ressalte-se que neste resultado apresentado aqui, o tema foi delimitado nas questões linguísticas da/na tríplice fronteira: Brasil, Paraguai e Argentina, com base nas proposições de Walter Mignolo, sobre o "plurilinguajeo".
\end{abstract}

Palavras-Chave: Damián Cabrera; fronteira; literatura paraguaia; plurilinguajeo.

\section{Resumen}

Este estudio es el resultado de la lectura y análisis de la obra del escritor paraguayo Damián Cabrera. La narrativa del dicho autor, presentada en este texto, es la novela Xirú. En esa obra, Cabrera presenta un mundo fronterizo como protagonista de la novela. La narrativa de Cabrera aborda el escenario fronterizo del Alto Paraná, donde las culturas se mezclan, pues, entre las muchas de las particularidades, la gente que habita ese lugar son nombradas "brasiguayos" (brasileños/paraguayos), que hablan una lengua nombrada "portuguarañol" (portugués/ guaraní/ español). Además de presentar más esta obra de la literatura hispanoamericana, esta investigación tiene el objetivo de echar luz sobre el "plurilinguajeo" que ocurre en este lócus. Vale resaltar que en este resultado presentado acá, el tema fue limitado a las cuestiones lingüísticas de la/ en la triple frontera: Brasil, Paraguay y Argentina, bajo a las proposiciones teóricas de Walter Mignolo sobre el "plurilinguajeo".

Palabras-Clave: Damián Cabrera; frontera; literatura paraguaya; plurilinguajeo.

\footnotetext{
${ }^{1}$ Artigo apresentado no Simpósio Temático 05 - Fronteiras Culturais em Contextos Epistêmicos Descoloniais II, durante o II Seminário Latino-Americano de Estudos em Cultura - SEMLACult em Foz do Iguaçu/PR, Brasil, 2018.

${ }^{2}$ Doutora em Literatura; Universidade Federal de Mato Grosso do Sul - UFMS; Campo Grande, Mato Grosso do Sul, Brasil; dpslbrasil@gmail.com.
} 


\begin{abstract}
This paper is the result of reading and analysis of the work of the Paraguayan writer Damián Cabrera. The narrative presented in this text is the novel Xirú. In this work, Cabrera presents a border world as the protagonist of the novel. Cabrera's narrative approaches the border scenario of Alto Paraná, where cultures mix, for, among many peculiarities, the people who live in this space are named "brasiguayos" (Brazilian/Paraguayan people), who speak a language called "portuguarañol" (Portuguese / Guarani / Spanish languages). In addiction to presenting more this work of Spanish-American literature, this paper aims to shed light on several concepts, such as border biographical criticism, borderlands literature, peripheral aesthetics and, especially, "plurilinguajeo" that occurs in this locus. It should be emphasized that in this paper, the theme was delimited in the linguistic questions of the triple frontier: Brazil, Paraguay and Argentina, based on the propositions of Walter Mignolo, on "plurilinguajeo".
\end{abstract}

Keywords: Damián Cabrera; border; Paraguayan literature; "plurilinguajeo".

\title{
1. Introdução
}

Antes de tratar das questões relacionadas ao tema, que são: fronteira e saber linguístico, necessário se faz apresentar a obra que exemplifica o que propõe este texto, que é o romance Xirú do escritor paraguaio Damián Cabrera, quem é um dos representantes da nova narrativa paraguaia, que em sua escrita dá ao espaço do seu país, especialmente o espaço da fronteira, um tratamento diferenciado.

O referido autor nasceu em Assunção, mas cresceu em Minga Guazú, no Alto Paraná, próximo à Ciudad del Este, cidade que faz parte do triângulo internacional conhecido como a Tríplice Fronteira: Brasil, Argentina e Paraguai. Em sua obra Cabrera apresenta esse mundo fronteiriço como protagonista do romance Xirú. Dita narrativa aborda o cenário fronteiriço do Alto Paraná, onde as culturas se misturam e entre muitas de suas peculiaridades, há o fato das pessoas que povoam esse espaço serem denominadas "brasiguayos" (brasileiros/paraguaios), que falam uma língua denominada "portuguarañol” (português/ guarani/ espanhol).

Cabrera apresenta esse mundo fronteiriço como protagonista do romance Xirú, abordando o cenário lindeiro do Alto Paraná, onde as culturas se misturam, um "lugar outro", termo apresentado pelo teórico latino-americano Walter Mignolo, lugar rico em diversidade que é povoado por "brasiguaios", que falam "portuguaranhol", é um lócus onde não se pode desmembrar pessoas e culturas, e tão pouco as línguas que aí são proferidas.

O escritor o transmite com diligência e com o conhecimento devido por ter sido testemunha dessa "colonização", e a criação de uma nova cultura alteradora e condicionante da vida na região. Cabrera apresenta ao leitor uma galeria de quadros que pintam a região da tríplice fronteira, com seus conflitos atuais, que são percebidos no olhar do escritor como uma certa desesperança opressora, pois parece não haver futuro para os jovens desse lugar, pois a narrativa a revela por diversas vezes com a frase: 'no hay nada que hacer'. À essa falta de 
esperança própria de uma juventude sem futuro, se une a tradição sobrevivente nos mitos e mentalidades e uma nova cultura surgida com a ruptura de fronteiras: tudo provoca a permeabilidade das mentes. É um romance complexo, pois seu discurso não é unitário, fluido, apresenta certa dispersão de cenas e situações bastante complexas.

\title{
2. Lócus de construção de saber
}

O lócus da narrativa de Xirú é a fronteira, que além de ser pensada como uma definição física, que separa, une, delimita, marca diferença ou semelhança e que também é pensada como produção de novos espaços de relações, deve ser pensada como espaço de construção de pensamento, saberes e conhecimento. Nesta análise a ideia de fronteira parte das reflexões que vem dos Estudos Culturais, que ultrapassam o caráter geográfico e geopolítico e o encaixa como um dispositivo essencialmente pedagógico:

\begin{abstract}
El carácter pedagógico relativo a la revisión de la noción de "fronteras" del conocimiento (cómo se produce y transmite) tiene como efecto fundamental la generación de epistemologías geoculturales desarticuladoras de las diferencias y asimetrías frente al poder. El cruce entre pedagogía crítica y ruptura epistemológica se constituye como fundacional en los estudios culturales. Esto quiere decir que lo que da lugar a estos estudios es, sobre todo, una nueva forma de administración y producción del conocimiento, cuya operación esencial es el cruce de fronteras disciplinarias y geoculturales. Lo que finca el carácter alternativo de estos estudios es la producción de una pedagogía política del disenso hacia fuentes hegemónicas de provisión de sentido disciplinario. Esta pedagogía -la del cruce, del desborde y de la transgresión de fronteras disciplinarias- contribuye al rediseño de una América Latina, que privilegia tanto un retorno crítico a lo regional y a lo local, como una propuesta de ciudadanías transnacionales o interculturales. (Diccionario de estudios culturales latinoamericanos, 2009, p. 106)
\end{abstract}

Ressaltar o lócus do autor é algo que se faz necessário, e para isso, valho-me da reflexão do teórico latino-americano Walter Mignolo quando trata da denominação "paradigma outro", porque Damián Cabrera não só compartilha o que outros viveram ou aprenderam no corpo, o trauma, a inconsciente falta de respeito, a ignorância, mas pode falar de direitos humanos e de convivência - de como se sente no corpo o "ninguneo" que os valores do progresso, de bemestar, de "bem-ser" impuseram à maioria dos habitantes do seu lócus. Seu nome conecta formas críticas de pensamento emergente. Essa fronteira onde Cabrera gesta Xirú também faz parte dos "Lugares outros", espaço de história, memória, dor, línguas e saberes diversos não é encarado por Cabrera, em sua obra como lugar de estudo, mas lugar de pensamento, onde se gera pensamento, onde se gera o "bilinguajeo" ou "trilinguajeo" e por que não dizer "plurilinguajeo" uma vez que não se trata apenas de português, guarani e espanhol, mas também de outras 
línguas que habitam essa fronteira. Além do fenômeno linguístico gestado neste espaço, também são geradas as epistemologias fronteiriças. Nesse espaço o sujeito pensa e é pensado.

O espaço fronteiriço de Brasil, Paraguai e Argentina descrito pelo autor é o protagonista do romance Xirú. O título do romance reproduz este termo guarani (che - iru, "mi amigo") adotado no português do sul do Brasil com este significado. Com um deslocamento de sentido neste nome, aborda o cenário fronteiriço do Alto Paraná, onde se misturam as cultura desses países. Esse cenário já ocupou outras obras da literatura paraguaia como Hijo de hombre (1960) de Augusto Roa Bastos, especialmente o Alto Paraná, que na obra é denominado por Takurú Pukú (la ciudadela del terror), Tierra de nadie - Ninguém (2000) de Augusto Casola e vale ressaltar El goto (1998) de José Eduardo Alcázar, neste caso manejando uma linguagem na qual se misturam as três línguas da região (espanhol, guarani e português) até criar um jargão próprio que Alcázar denomina "portuguarañol”. Inclusive criou-se um nome para os habitantes que misturam ambas línguas: "brasiguayos". Também Rafael Barret em sua obra Os ervais, descreve este espaço. Este lócus fronteiriço sempre foi dominado pelo patrão, das companhias ervateiras e até hoje pelos plantadores de soja, representado em Xirú pelo senhor Washington dos sojales.

O aumento do contato entre Brasil e Paraguai através do Alto Paraná é patente, até o ponto de se formar uma vida neocolonial brasileira em determinados pontos da região, fomentados pelo trânsito econômico rural e o exacerbado comércio da capital, Ciudad del Este. Na década de 1960 esses brasileiros em busca de estabilidade na terra, migram para esse espaço - vale ressaltar que em sua maioria são brasileiros de origem alemã, italiana e eslava, falantes de português - representa a evolução de um mundo aberto digno de se converter em representativo de uma época.

\section{Portuguarañol: Bilenguajeo/ Plurilenguajeo}

Esse lugar rico em culturas e línguas, como se descreve acima, leva-nos a refletir com Walter Mignolo (2003, p. 29), que há economias fortes, economias fracas, economia desenvolvida e subdesenvolvida, economias emergidas (já emergiram), economias emergentes. Processo semelhante também ocorre no âmbito das línguas, pois segundo o teórico supracitado, há línguas de conhecimento (inglês, francês e alemão); Línguas de tradução do conhecimento (espanhol, italiano e português); Línguas de tradução, mas também coloniais (o castelhano na 
América Latina ou o spanglish nos Estados Unidos); Línguas de cultura (aymará, bengali,); Línguas entre a tradução e a cultura (chinês, árabe, hindu).

Em Xirú vemos que não se pode falar de língua com a perspectiva que não seja de um “outro paradigma”, pois não estamos diante de um cenário em que só se utilizam a língua de cultura, que é o guarani, mas sim de um cenário onde línguas de conhecimento, como inglês e alemão se apresentam através do gringo, o patrão norte-americano e o alemão. Língua de tradução de conhecimento, o espanhol e o português e sobretudo de tradução, que também são coloniais, representadas aqui pelo castelhano latino-americano. Há ainda as que estão entre a tradução e a cultura, o chinês, o árabe, etc.

O autor ainda se vale da oralidade, pois seu texto está constituído pela predominância de extratos da modalidade oral das línguas portuguesa, guarani e esapnhola, isso porque em Xirú é dado privilégio à voz do excluído, do marginalizado, das minorias, ou seja do excêntrico. A oralidade deve ter sido considerada por Cabrera uma vez que essa modalidade consegue ressaltar a importância de memórias subterrâneas, memória que se opõe à memória oficial. (Michel Pollak, 1989, p. 4).

Na cultura paraguaia a tradição oral é muito relevante e aqui cito outro escritor paraguaio, Augusto Roa Bastos, que em sua obra Yo el Supremo, diz que a tradição oral é a única linguagem que não se pode saquear, roubar, repetir, plagiar, copiar. Lo hablado vive sostenido por el tono, los gestos, los movimientos del rostro, las miradas, el acento, el aliento de quien habla. (ROA BASTOS, 2008, p. 89). Xirú parece alcançar o objetivo de representar o descrito acima por Roa Bastos, já que se percebem muitas vozes com características da modalidade oral das línguas.

Para tratar da questão do "plurilenguajeo" em Xirú, faz-se necessário refletir sobre a questão da fronteira, e aqui não se pode falar em fronteira como espaço físico, mas também e necessariamente como pensamento e construção de outras epistemologias. Nessa fronteira física e epistemológica foi gestada uma língua híbrida, onde se misturam português, espanhol, guarani e muitas outras, já que a convivência nesse espaço não se limita a paraguaios e brasileiros, mas convivem aí o empresário e comerciante chinês (asiático) e o árabe, também povoam esse lugar, o senhor dos campos de soja e de erva, o norte-americanos e também o europeu. Ressalte-se ainda a modalidade oral das línguas que permeia todo o discurso nessa comunidade, e que é muito bem retratada no romance aqui analisado. 
Além de se estar em um ambiente de natureza híbrida, vale lembrar que o Paraguai é um país, possui duas línguas oficiais, o castelhano e o guarani, particularidade observada em poucos países da América Latina, pois muitos países falam mais de uma língua, mas no Paraguai, a língua da nação indígena, passou a ser língua oficial a partir da Constituição de 1992, e portanto, passou a ser ensinada nas escolas, saindo assim da restrição ao âmbito familiar. No imaginário coletivo do povo paraguaio, está gravado que o espanhol/ castelhano é língua de negócios e do patrão, já o guarani é a língua do coração, a que expressa sentimentos.

A questão linguística do Paraguai é tema de muitas investigações, um exemplo são os estudos de Bartolomé Meliá sobre a mistura de línguas, fenômeno que recebe o nome de 'yopará', palavra guarani, que vem da gastronomia, já que é o nome de um prato onde se misturam vários ingredientes, que significa mescla. Mas, em Xirú, não há uma descrição do Paraguai, mas sim de um espaço, como já fora apresentado, como de diversidade de nações e línguas, por isso o caminho a percorrer será sob as proposições de Walter Mignolo, "Paradigma otro", "Lugar otro", pois a obra trata de um lócus que não pode ser visto à luz de teorias que não pensam a fronteira e especialmente o espaço latino-americano.

O texto de Damián Cabrera não trata da tensão entre guarani, português e espanhol, como em diversas obras de autores latino-americanos em outros tempos. Em Xirú, língua, literatura, cultura e nação se relacionam também com a ordem geopolítica e as fronteiras geográficas. (MIGNOLO, 2003, p. 292).

Mignolo ao tratar sobre as línguas e suas implicações na literatura, num mundo transnacional, apresenta reflexões sobre a plurilinguagem. El plurilenguaje capta mejor una situación que se ha definido, desde la perspectiva de las ideologías nacionales, en la oposición entre "lenguas extranjeras" y "educación bilingüe”. (MIGNOLO, 2003, p. 293). Cabrera compõe sua obra sob a égide dessas reflexões, pois seu romance ilustra o que o mundo contemporâneo tem vivido desde as últimas décadas do século XX: uma relocalização de línguas e culturas que se fez possível pelo próprio processo de interconexão global. O que ocorre no cenário desenhado em Xirú é exatamente o que Mignolo considera como processo de mercantilização, contrário aos processos de civilização e cristianização que ocorriam antes do último quarto do século XX, quando diz que:

La colonialidad sigue siendo, en este dominio global, una fuerza innominada, no dicha, de modernización y mercado. Paradójicamente, el énfasis en el consumismo, los bienes de consumo y los mercados juega contra el control impuesto por los primitivos programas cristiano y civilizador. (MIGNOLO, 2003, p.294) 
O autor de Xirú produz uma literatura que é o exemplo de um conhecimento e um pensamento fronteiriço, já que mistura em sua escrita, o português, o guarani e o espanhol. Por si só o discurso em Xirú é híbrido e mantem a heterogeneidade da fronteira, pois a prática literária de Cabrera não se concebe como objeto de estudo, mas sim como produção de conhecimento teórico, não como representação de algo, sociedade ou ideias, mas como reflexão especificamente própria sobre os problemas humanos e históricos, como sugere a reflexão de Mignolo quando se refere ao lugar onde se podem encontrar as teorias.

Esto incluye, naturalmente, a la lengua, no necesariamente en términos de gramática o fonética, sino de política lingüística, atendiendo a las distintas formas en que las prácticas literarias se han vinculado, en el sistema-mundo moderno/ colonial, a la colonialidad del poder en sus versiones colonial y nacional. La lengua también implica la cuestión de la formación de cánones, la forma en que se han entretejido los valores nacionales y occidentales para producir mapas lingüísticos, geografías históricas y panoramas culturales del sistema-mundo moderno/ colonial dentro de su lógica interna (conflictos imperiales) así como en sus fronteras externas (conflictos con "otras" culturas; la diferencia colonial). (MIGNOLO, 2003, p. 298)

Não se discute que em Xirú não há a preocupação em preservar a pureza linguística de nenhuma das línguas, já que se observa que as línguas se expressam tal como se utilizam na fronteira e em qualquer contexto de oralidade. Cabrera pensa e escreve entre línguas, com a ideia de língua como prática cultural e luta pelo poder, não levando em consideração o sistema de regras sintáticas, semânticas e fonéticas, mas considerando a ideia de que fala e escrita são estratégias para orientar e manipular campos sociais de integração, como pontua Mignolo, 2003:301, quando trata de El desacoplamiento entre la lengua y la literatura nacional.

\section{Conclusões}

Não trato aqui de concluir o texto, pois há muito que se dizer sobre a obra ora apresentada, mas o mais interessante aqui é a proposta de se refletir sobre as questões da fronteira como lugar de construção de saberes, lugar onde os sujeitos pensam e são pensados. Também continuar as reflexões sobre as questões de linguagem na fronteira, pois a língua se mostra como estratégia de articulação nas relações sociais e de poder. Ao tratar do tema da fronteira, levanta-se a necessidade de continuidade sobre o tema, fazendo uma análise da obra de Damián Cabrera, partindo de um dispositivo pedagógico dentro dos estudos fronteiriços. Por isso a investigação através da leitura e análise de Xirú continuará. 


\section{Referências}

CABRERA, Damián. Xirú. Assunción: Ediciones de la Ura, 2012.

Diccionario de estudios culturales latinoamericanos / coordinación de Mónica Szurmuk y Robert McKee Irwin ; colaboradores, Silvana Rabinovich ... [et al.]. — México : Siglo XXI Editores : Instituto Mora, 2009. 332 p.

MIGNOLO, Walter. Historias locales/ Diseños globales. Colonialidad, conocimientos subalternos y pensamiento fronterizo. Madrid: Ediciones Akal, 2013

POLLAK, Michael. Memória, esquecimento, silêncio. Trad. Dora Rocha Flaksman. In: Estudos históricos, vol. 2, n. 3, 1989.

ROA BASTOS, Augusto. Yo el Supremo. Buenos Aires: Debolsillo, 2008. 